Article

\title{
Analysis of Green Spaces by Utilizing Big Data to Support Smart Cities and Environment: A Case Study About the City Center of Shanghai
}

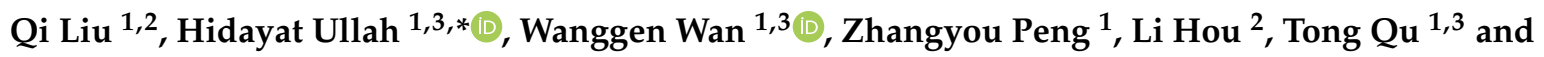 \\ Saqib Ali Haidery 1,3 \\ 1 School of Communication \& Information Engineering, Shanghai University, Shanghai 200444, China; \\ liuqi@shu.edu.cn (Q.L.); wanwg@staff.shu.edu.cn (W.W.); zypeng@mail.shu.edu.cn (Z.P.); \\ qu_tong@shu.edu.cn (T.Q.); alisaqib@shu.edu.cn (S.A.H.) \\ 2 School of Information Engineering, Huangshan University, Huangshan 245041, China; houli@shu.edu.cn \\ 3 Institute of Smart City, Shanghai University, Shanghai 200444, China \\ * Correspondence: hidayat@shu.edu.cn
}

Received: 1 April 2020; Accepted: 30 May 2020; Published: 1 June 2020

\begin{abstract}
Green areas or parks are the best way to encourage people to take part in physical exercise. Traditional techniques of researching the attractiveness of green parks, such as surveys and questionnaires, are naturally time consuming and expensive, with less transferable outcomes and only site-specific findings. This research provides a factfinding study by means of location-based social network (LBSN) data to gather spatial and temporal patterns of green park visits in the city center of Shanghai, China. During the period from July 2014 to June 2017, we examined the spatiotemporal behavior of visitors in 71 green parks in Shanghai. We conducted an empirical investigation through kernel density estimation (KDE) and relative difference methods on the effects of green spaces on public behavior in Shanghai, and our main categories of findings are as follows: (i) check-in distribution of visitors in different green spaces, (ii) users' transition based on the hours of a day, (iii) famous parks in the study area based upon the number of check-ins, and (iv) gender difference among green park visitors. Furthermore, the purpose of obtaining these outcomes can be utilized in urban planning of a smart city for green environment according to the preferences of visitors.
\end{abstract}

Keywords: geospatial visualization; big data; kernel density estimation; green parks; geospatial knowledge; smart cities

\section{Introduction}

Urban areas are generally marked by downgraded ecosystems, rising environmental damage, higher temperature, and a decreasing number of green parks. Urban green spaces (UGS) are important for improving quality of life in metropolitan areas, balancing thermal comfort with thermal budget [1], and helping the public heal from the physical and emotional pressures of their daily lives [2]. Green spaces in an urban environment are vital for improving living conditions by improving air quality and aesthetics, which eventually lead to higher real-estate values and a reduction in energy use for cooling. Urban green spaces can also be applied as a cumulative resource for enhancing the sustainability of urban areas [3]. They also provide children with much-needed space to play, significant for their social, cognitive, and mental functions [4].

Urban green spaces-in general, parks—offer many advantages to people's well-being, such as psychological and social well-being and physical health [5-7]. Visits to green parks provide an opportunity to experience the extra benefits of "natural" environments directly, especially for people with limited natural contact. Consequently, quantifying the visits of residents to urban green 
spaces and recognizing the factors that influence their visits are vital for urban park management and planning. It is important to measure visitation of parks and urban green spaces to recognize their recreational interests and define the factors that influence them. Visitor polls, on-site counters, and direct observation are traditional methods for estimating the number of visitors [8,9]. These methods of organized observation usually pick a representative sample of urban green spaces and collect information about green park use-for example, visitation numbers and features, activities, and behavior of green park visitors. However, these approaches are typically time-consuming and site-specific and, therefore, have restricted spatial coverage [10]. The advent of free social media data offers new methods of calculating urban green park visits. Data collected from social media and other "big data" reliable sources grow in size every year and can be utilized to research how the public interact with actual environments and to accurately assess individual preferences through time and space [11].

The World Health Organization (WHO) reports on the environment, urban planning, and health released in 2010-2016 reveals that green spaces can positively affect physical activity, social and psychological well-being, improve air quality, and reduce the exposure to noise [12,13]. Epidemiological research has used a wide range of methods to calculate the positive impact of green parks' accessibility and availability on health. Due to the ability of urban green spaces to act as an environment for promoting health, it is essential to summarize available evidence, recognizing, where possible, the underlying mechanisms that contribute to positive and negative health outcomes of green spaces. Recent developments in social media analysis based on geographic information systems (GIS) provide an opportunity to examine spatial and temporal, and even affective dimensions of the behavior of users, including public spaces and visits to parks $[14,15]$. However, some of these analyses still have drawbacks, because only a relatively small number of social media posts are analyzed manually.

The kernel density estimation (KDE) method was used to model geolocation data spatially and offers an additional particular and comfortable structure for spatial estimation of density. The method was used for the assessment of environmental attributes-for example, healthcare properties [16], the diet environment [17], and green space advantages. It boosts access or measuring distance by transforming point data into something similar to a nonstop surface and allowing the density of the characteristic to be measured at any point on the map's surface [18]. In this research, we expected to examine the effects on visitation rates of users' check-in behaviors to green spaces. We utilized a sample of data to research green park-related check-in behaviors, including likes and dislikes, as a summary of the behavior or preferences of the general public in various activities while using park resources. Similarly, the aim of the study is to address the following questions: (i) Is using the social media network dataset feasible for this kind of environmental studies? (ii) How often does the time of day influence the behavior of the general public in green parks? (iii) Which district is the center of activities in the city center of Shanghai? To properly grasp the link between green parks and visitor behavior, we analyzed users' spatiotemporal trends in urban green spaces using a large-scale dataset from July 2014 to June 2017, with almost 70,000 check-ins. Our main results indicate the user check-in distribution in different green parks and exciting behavioral changes based on the time of day in 24 hours and the day of the week. We also investigated the gender difference among districts and days by applying the relative difference formula. By examining these factors, we could analyze the use of urban green parks and its variance across a range of temporal scales. This method of capturing visitor activity in urban green spaces is an attempt to solve the drawbacks of previous studies. This method paves the way for socioecological research using crowdsourced and social network data instead of relying on the results of subjective coverage and observational data. 


\section{Materials}

\subsection{Study Area}

Shanghai City is among the fastest-growing metropolises in the world, with a population of $22,125,000$ in an area of $4015 \mathrm{~km}^{2}$ [19]. The overall number of green parks within the city of Shanghai is 366 [20]. As part of the alluvial plain, Shanghai and the Yangtze River Delta have an average elevation of around $4 \mathrm{~m}$. From east to west, there is a slight terrain gradient. The land is plain, except for some southwesterly foothills. Shanghai is part of the climate zone for the north subtropical humid monsoon. There are four seasons with abundant sunshine and rainfall. Therefore, in such a metropolitan area, extreme events and urbanization have had a substantial influence on public health-promotion services and the country's economy. Shanghai is indeed the world's tenth-most prominent agglomeration region. It also states that the process of urbanization is relatively quick. The United Nations (UN), in its future forecasts of urbanization, stated that Shanghai's urban population ranks as the world's second-largest and China's largest [21]. Figure 1 represents the study area.

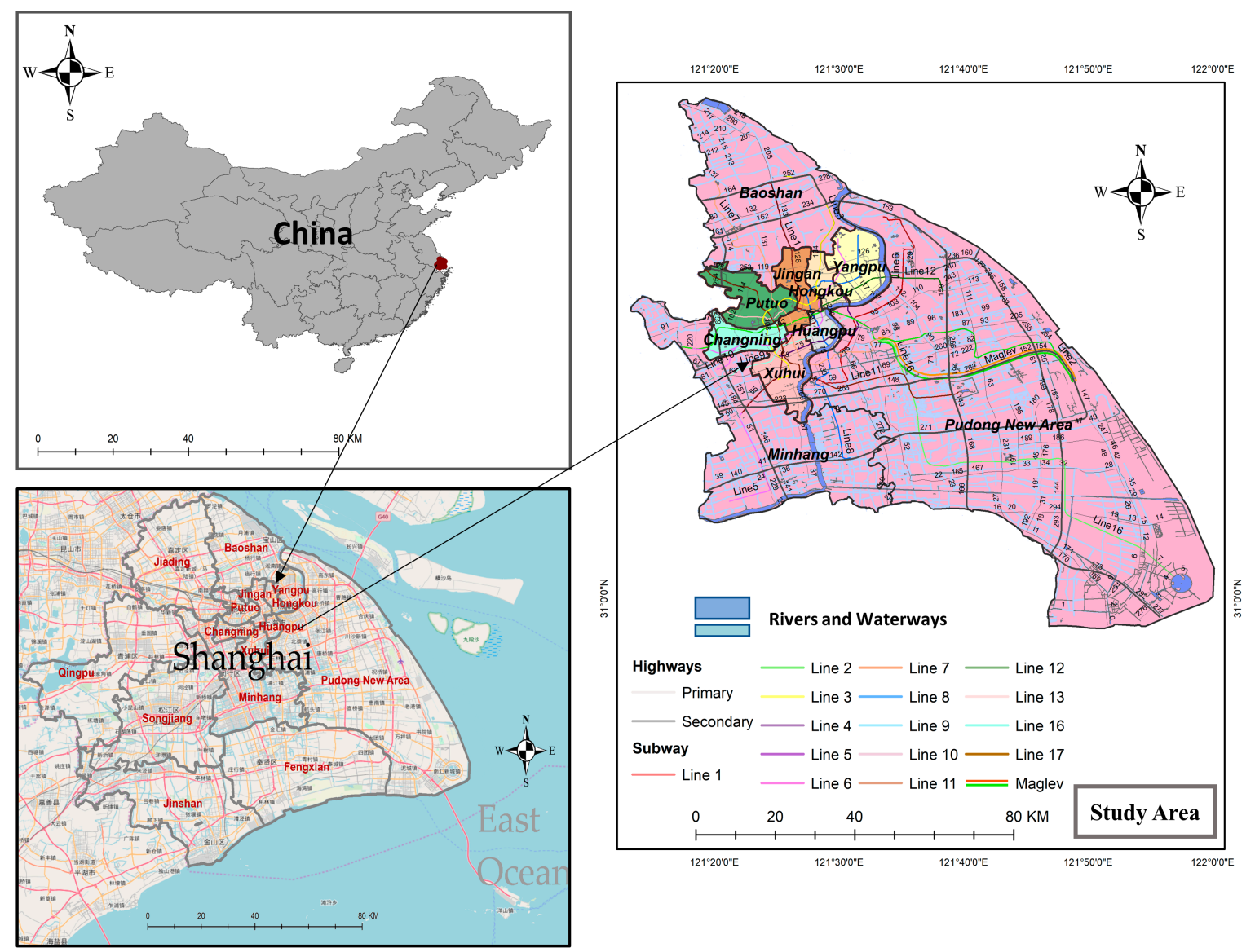

Figure 1. Study area.

In 2016, Shanghai was divided into 16 districts: 15 districts (Baoshan, Changning, Fengxian, Hongkou, Huangpu, Jiading, Jing'an, Jinshan, Minhang, Pudong New District, Putuo, Qingpu, Songjiang, Xuhui, and Yangpu) and 1 county (Chongming) [22]. Seven regions (Changning, Hongkou, Huangpu, Jing'an, Putuo, Xuhui, and Yangpu) are located in Puxi (literally Huangpu West) and are known as Shanghai's downtown or city center $[23,24]$. 


\subsection{Dataset}

The dataset that we used to examine the number of visits to green parks comes from the Chinese popular microblog Weibo. Weibo is considered to be comparable to China's Twitter and the major social media blog in China. The amount of Weibo customers is huge, representing the biggest dataset of obtainable geotags. According to its latest annual report, Weibo announced that more than 500 million active users registered on the platform in 2018 and reached 462 million monthly active users in December 2018 [25]. The demographics of Weibo users are inconsistent with the total population. It was decided to launch the public interface of the Weibo location-based service (LBS) on May 28, 2012. Weibo users have since been able to share their location on the internet in real-time. As a kind of scalable and available large-scale crowdsource data, Weibo sign-in data are the most appropriate dataset we could obtain to estimate the actual number of park visitors. However, an earlier study of 87 city parks situated in Shanghai, China showed that there was an important link between data from Jiepang social media platforms and official visit numbers [26].

\subsection{Dataset Filtaration}

In this part of the procedure, improper data were distinguished, filtered, and modified to avoid incorrect conclusions. Preprocessing consisted of cleaning out unrelated columns, eliminating duplicate rows, resolving discrepancies, and performing data management, allowing improved data interpretation in the analysis method. We also translated the data, because the dataset was written in the Chinese language, so it was necessary to first change it to English as can be seen in Table 1.

Table 1. Transformation.

\begin{tabular}{cccccc}
\hline \multicolumn{1}{c}{ Location ID } & Lat. & Long. & Category/EN & Location Name & District \\
\hline B2094757D068A2FB469E & 31.00728 & 121.4233 & park & Minhang Park & Minhang \\
B2094654DB6EABFC459E & 31.03845 & 121.4096 & park & Quinta Park & Minhang \\
B2094757D06FA4F9439F & 31.11351 & 121.5968 & park & Zhoupu Park & Pudong \\
B2094655D268A7FB419A & 31.02493 & 121.2308 & park & QICHANG Park & Songjiang \\
B2094757D068A6FE4799 & 31.03036 & 121.2238 & park & Sixian Park & Songjiang \\
\hline
\end{tabular}

Weibo was created in August 2009 and is one of China's largest social media sites and a popular microblogging platform that allows people to post and share their daily activities with their circle of friends. The term "check-in" shows that a user willingly wants to share or proves their location on the LBSN by publicizing it on a location-sensing smartphone or tablet while participating in certain activities [27]. Using the check-in data of Weibo [28], a new model was proposed that integrated the parameters of an urban environmental function network, thereby enriching the definition of the structure of urban networks. However, although using Weibo check-ins as a visit proxy is still uncommon, earlier research utilizing data from similar social media sites or platforms-for example, Facebook, Flickr, and Instagram-found important beneficial links between official visit stats and the amount of visitors reported on these sites. However, due to the unavailability of Facebook and the fact that Weibo is also considered the Chinese Facebook, we considered Weibo data to be the best source for this study $[10,29]$.

We also collected population data from the census of Shanghai [30] on the districts in the study area, as presented in Table 2. Figure 2 represents the criteria that we deployed for collecting the check-ins. 
Table 2. Area and population in the districts.

\begin{tabular}{cccc}
\hline District & Area $\mathbf{( k m}^{\mathbf{2}}$ ) & Population (per 10,000) & Check-Ins \\
\hline Putuo & 54.83 & 128.47 & $20.93 \%$ \\
Jingan & 36.88 & 106.62 & $10.24 \%$ \\
Hongkou & 23.46 & 79.90 & $7.79 \%$ \\
Yangpu & 60.73 & 131.34 & $16.98 \%$ \\
Huangpu & 20.46 & 65.48 & $17.48 \%$ \\
Changning & 38.3 & 69.37 & $13.43 \%$ \\
Xuhui & 54.76 & 108.83 & $13.15 \%$ \\
\hline
\end{tabular}

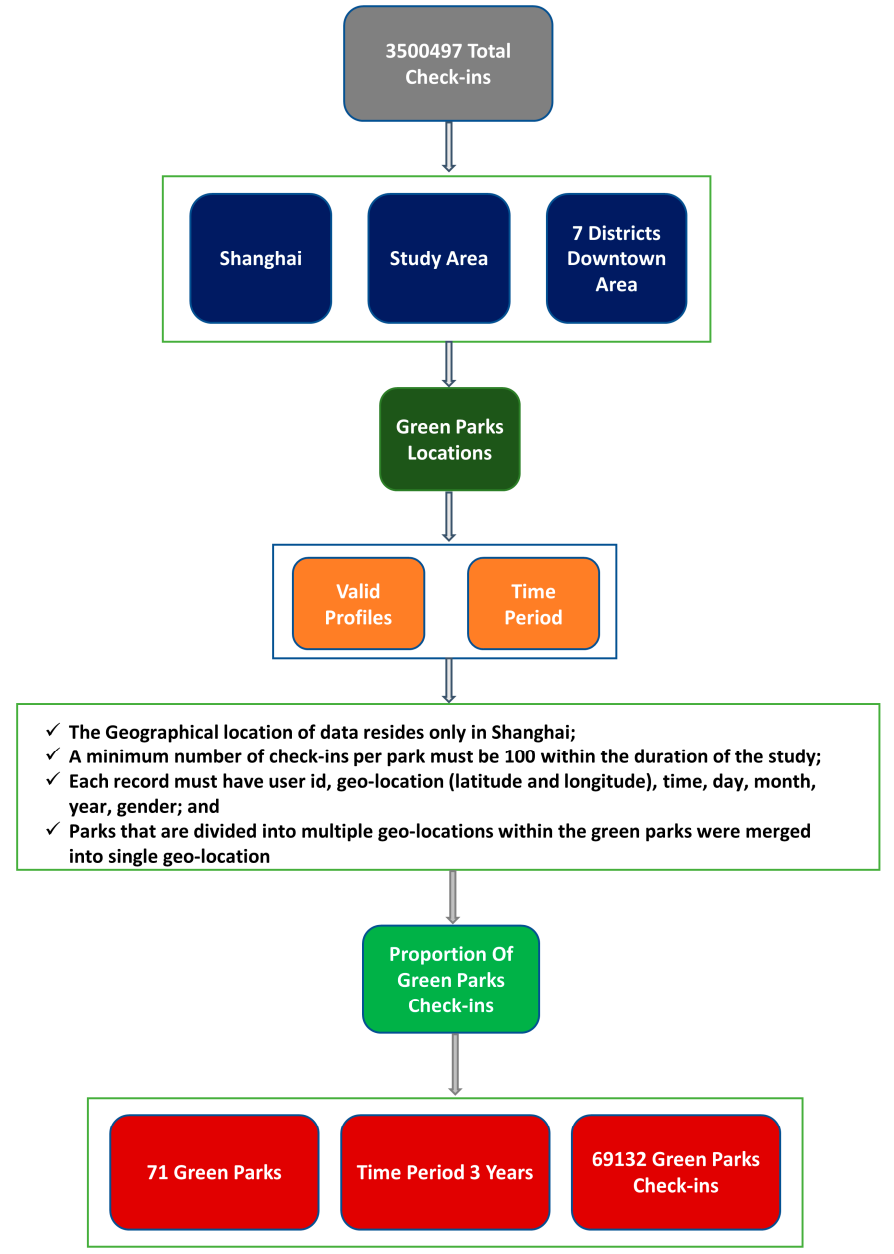

Figure 2. Criteria.

The Weibo application program interface (API) helps with data collection. After retrieving this location information, we found that some locations we added were not green parks (e.g., sidewalks, former homes of famous people, and sculptures). We checked these locations and removed those that were not in the green park category, but we still counted a part of the parking lot or park areas that were linked. Some larger parks have more than two location IDs-for example, a garden area, kids' play area, and barbecue area combined into one location ID [31]. After preprocessing, filtration, and cleaning, a total of 69,132 geotagged visits to green parks in 7 districts of Shanghai were included. The data were collected with the help of Python (version 2.7.12). 


\section{Methodology}

\subsection{Data Preparation}

The data that we collected cover all check-ins made within the Shanghai boundary. The data downloaded were included in many JSON files. Figure 3 presents the data preparation process flow.

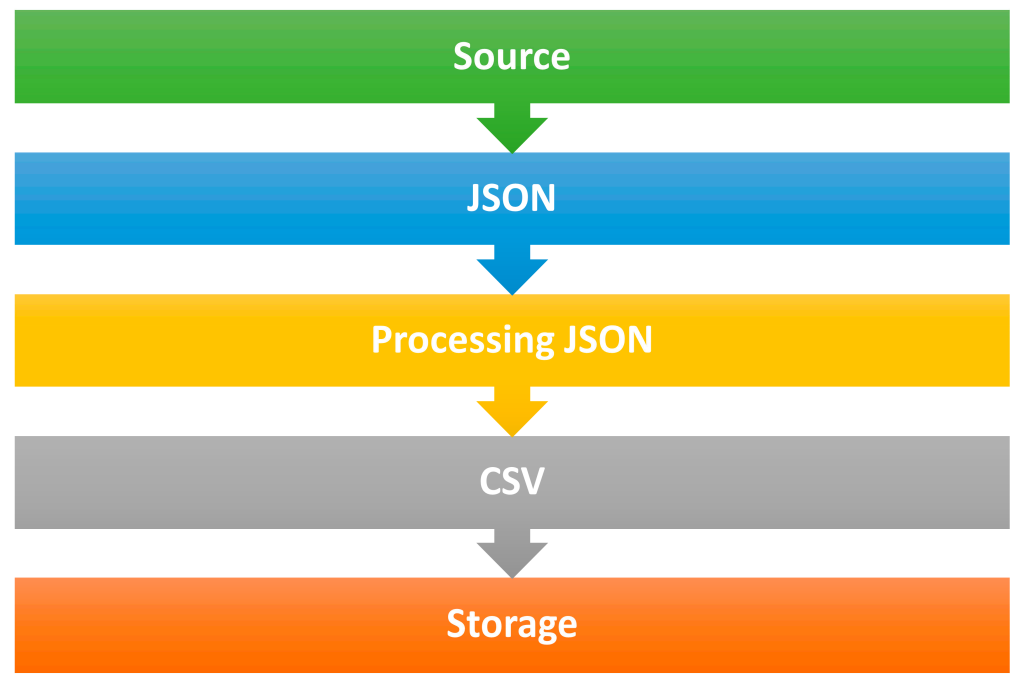

Figure 3. Data process flow diagram.

In this study, the Weibo dataset included a unique user ID, check-in, date, and time. In addition, information about the geographic location (latitude and longitude) and gender were collected through the Weibo API. The LBSN dataset therefore assumes that daily trends are archived of the users' daily activities, behavior on social media, and spatiotemporal evidence [32]. A typical Weibo check-in is represented as follows: check-in (B2094554D064ABF44293) $=\{1758115961$, \#\#\#\#, B2094554D064ABF44293, Mon July 25 14:47:41 +0800 2016, m, and 121.484566, 31.270601\}, where B2094554D064ABF44293 denotes "location_id"; 1758115961 denotes "user_id"; \#\#\#\# denotes "user_name"; Mon July 25 14:47:41 +0800 2016 denotes "day, month, date, time, and year"; m denotes "gender"; and 121.484566, 31.270601 denotes the "geolocation". Further, JSON is a Java programming platform format that is the most-commonly used data format, although Java is considered to be the main programming language with open-source accessible reader and writer modules. [33,34] Using selected software, the data were filtered into a comma-separated values (CSV) file format, so that all user data, which included the geolocations, could be identified and stored in the database regardless of the publication date. Table 3 shows an example of a check-in in CSV file format.

Table 3. Example of Weibo check-in.

\begin{tabular}{|c|c|c|c|c|c|c|c|c|c|c|}
\hline Building_id & User_id & Month & Date & Day & Time & Year & Gender & Long. & Lat. & Address \\
\hline B2094554 & & & & & & & & & & \\
\hline $\begin{array}{c}\mathrm{D} 064 \mathrm{ABF} \\
4429\end{array}$ & \#\#\# & 08 & 24 & Wed & 0:00:03 & 2016 & $\mathrm{~F}$ & 121.6650 & 31.14363 & ZhaoHang_Park \\
\hline В2094757 & & & & & & & & & & \\
\hline $\begin{array}{c}\text { D06FA0F } \\
8409 \mathrm{D}\end{array}$ & \#\#\# & 11 & 11 & Frit & $1: 24: 45$ & 2016 & $\mathrm{~F}$ & 121.5244 & 31.265614 & Jiangpu_Park \\
\hline В2094757 & & & & & & & & & & \\
\hline $\begin{array}{c}\text { D06FA6F } \\
\text { B409B }\end{array}$ & \#\#\# & 05 & 29 & Mon & 3:02:19 & 2017 & $\mathrm{M}$ & 121.3787 & 31.34228 & Gucun_Park \\
\hline
\end{tabular}




\subsection{Social Media Data Analytics}

In this research, we have analyzed Weibo-based geolocation datasets in 7 districts of Shanghai, China (July 2014 to June 2017). Figure 4 shows a check-in behavior analysis framework in which the LBSN data analysis method includes the framework, data preprocessing and cleaning, temporal, and spatial analyses of the LBSN data and statistics to deliver the worth of the LBSN data.

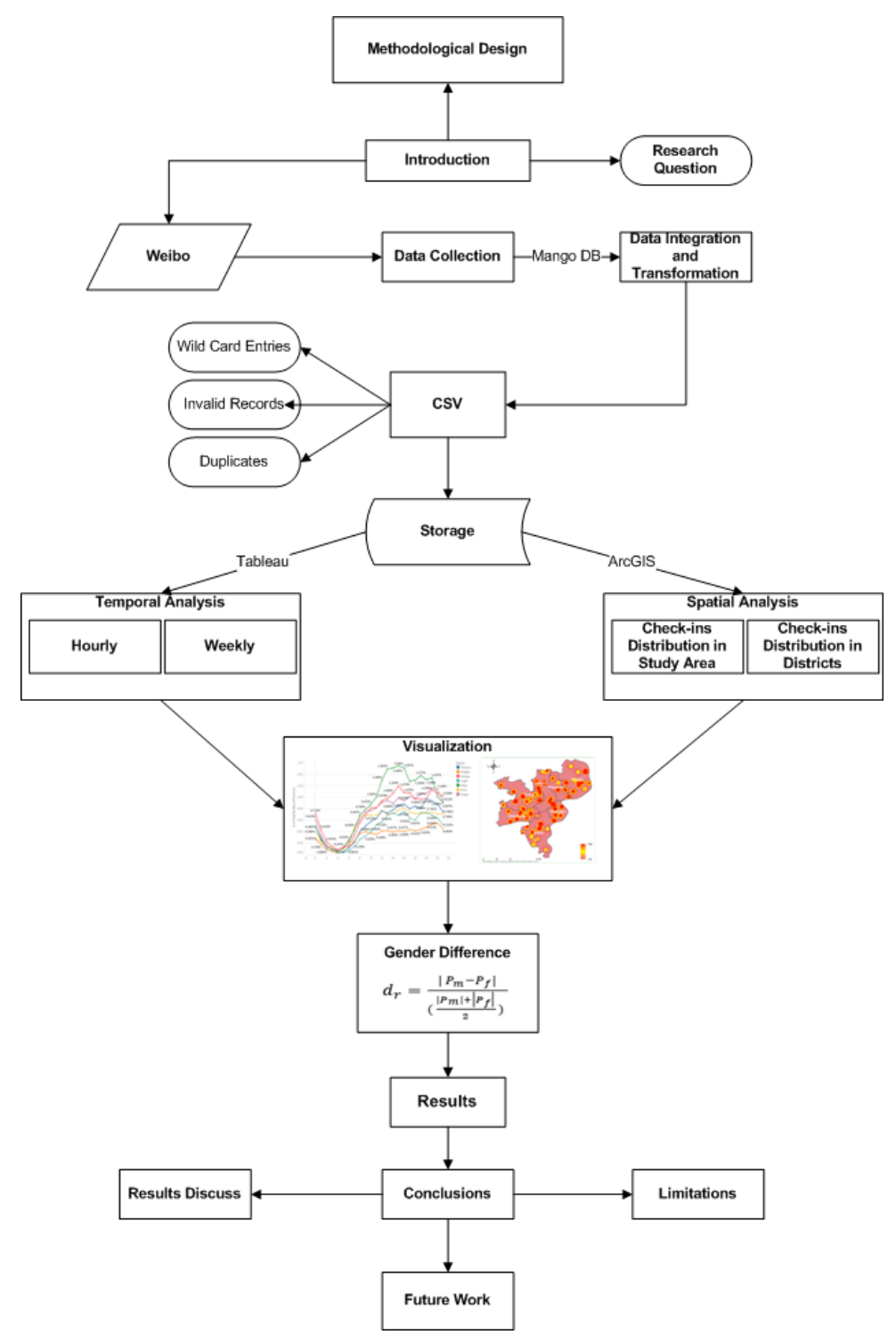

Figure 4. Data processing.

\subsection{Temporal Analysis}

To track variations in user behavior, we divided time stamps with check-ins into different time classifications. Daily patterns show the hourly distribution of check-ins during the day. First, we divided the timestamps for 24 hours according to check-in data for knowing the peak time of visitors in green parks. Secondly, we divided the check-in data according to numbers for daily stamps to know the accurate visitation rate for weekdays and weekends. We used Tableau 2019.2 for the visualization techniques to explore and analyze the relational databases and data cubes. 


\subsection{Spatial Analysis}

Kernel density estimation is effective in calculating the visitor density spatial structure within the study area. It is a statistical method for estimating a smooth and continuous distribution from a small number of observations. We utilized this method to create a smooth surface density for check-in hot spots in the geographic area. The method is a nonparametric estimation technique for the density of a random sample of data [35] and smooths each data point into small density bumps, after which, all the small bumps are combined to make a final estimation of the density. The KDE method has been widely accepted for spatial distribution [36-38]. It describes the spatial density distribution combined with the distance-decay effect and projects the hotspots by transforming scatter point data into a continuous density surface [39]. The KDE technique is an evolving spatiotemporal means that has previously been used [40-42] to inspect several features of social media (but not restricted to LBSN) data analytics such as users' online activity and movement trends [43], check-in behavior [44], city boundary descriptions [45,46], and point-of-interest recommendations [47]. It also explores the distribution of destinations in communities, enabling researchers to see where there are densely scattered destinations and where they are more scattered. Eventually, this seeks to create a smooth surface of density within the geographical space of spatial point cases [33]. The authors utilized the KDE method for the analysis of spatiotemporal patterns in green parks [48]

The data taken into account in our analysis are in the form of geotagged check-ins. Let " $E$ " be a collection of historical data for check-in; that is, $E=\left\{e^{1}, \ldots \ldots, e^{n}\right\}$, where $e^{i}=\langle x, y\rangle$ is a check-in geolocation $1<i<n$ of individual $i$ and on time " $t$ ", where " $E$ " represents the dataset we used. The total of the kernel's functions is scaled to construct a smooth curve that is a unit field. This results in a bivariate of $\mathrm{KDE}$ in the following form:

$$
\begin{gathered}
f_{K D}(e \mid E, h)=\frac{1}{n} \sum_{i=1}^{n} K_{h}\left(e, e^{i}\right) \\
K_{h}=\frac{1}{2 \pi h} \exp \left(-\frac{1}{2}\left(e, e^{i}\right)^{t} \sum_{h}^{-1}\left(e, e^{i}\right)\right)
\end{gathered}
$$

where " $e$ " denotes the check-in location in dataset " $E$ ", along with bandwidth " $h$ "; " $h$ " is supposed to be reliant on the estimated density " $f_{K D}$ ", producing a smooth density surface around " $E$ " at the data point " $e$ ".

ArcGIS 10.0 was used to evaluate the spatial distribution of the check-ins in space. We used ArcGIS 10.0 (Environmental Systems Research Institute, Inc., Redlands, CA, USA) software with a Shanghai map developed in 2016 using the WGS 1984 geodesic coordinate system. The base map also included major transportation lines (line layer) and administrative districts (polygon layer and district layers) with new OpenStreetMap subway lines and entries (point layer).

\section{Results}

For this analysis, 71 green parks locations were chosen after processing the data collected from Weibo in the city center. The distribution of different green parks included in this research is shown in Figure 5. 


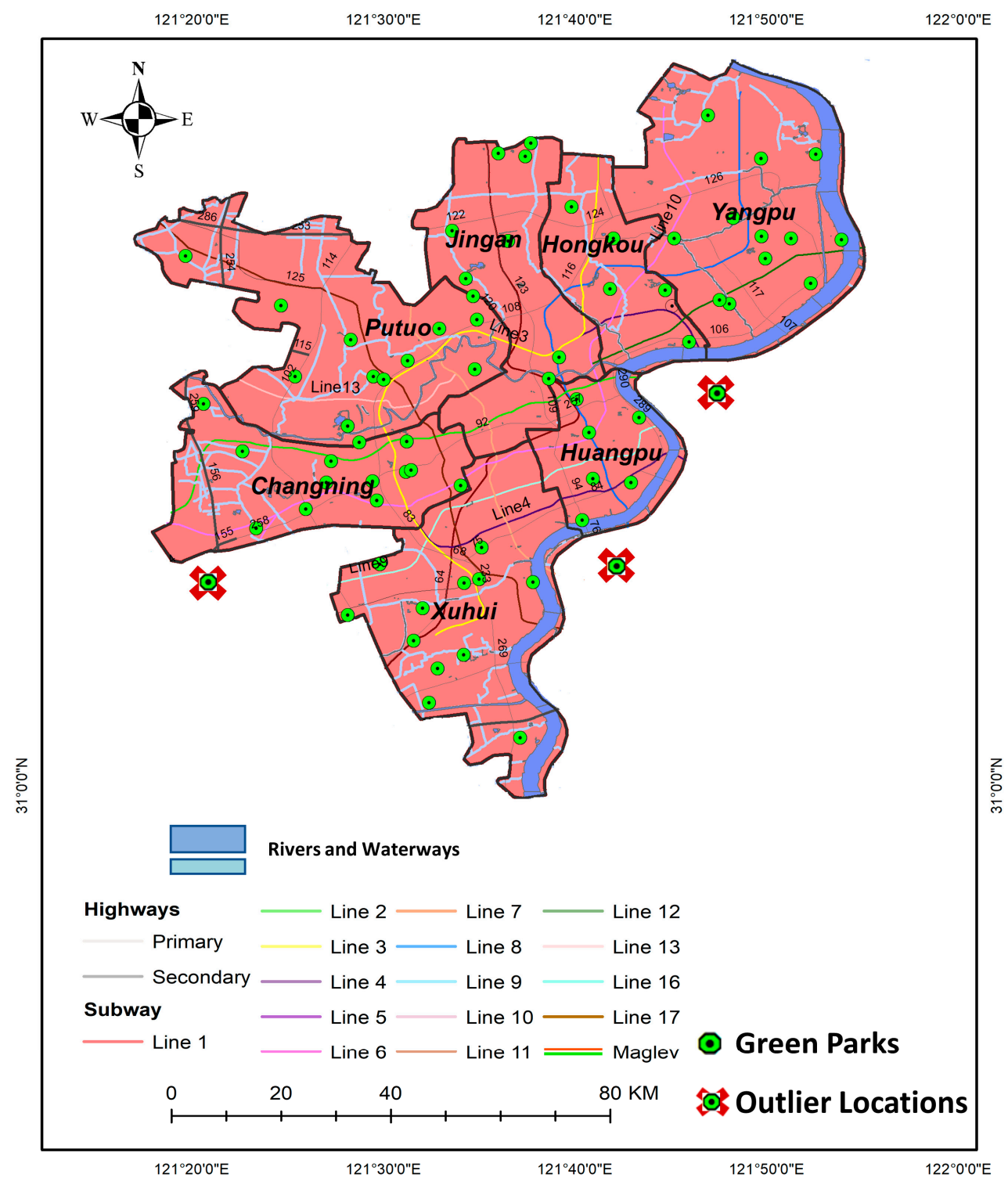

Figure 5. Parks and outlier locations in the study area.

As can be seen, there are some outlier locations. We had a dataset of Shanghai, and our study area was based upon the city center, which is why there were some outlier locations that came with the overall Shanghai check-ins. However, after filtration, only locations within the study area were chosen. As per the requirements and for significance, the locations that were among the study area criteria of seven districts (Changning, Hongkou, Huangpu, Jingan, Putuo, Xuhui, and Yangpu) are represented in Figure 6. 


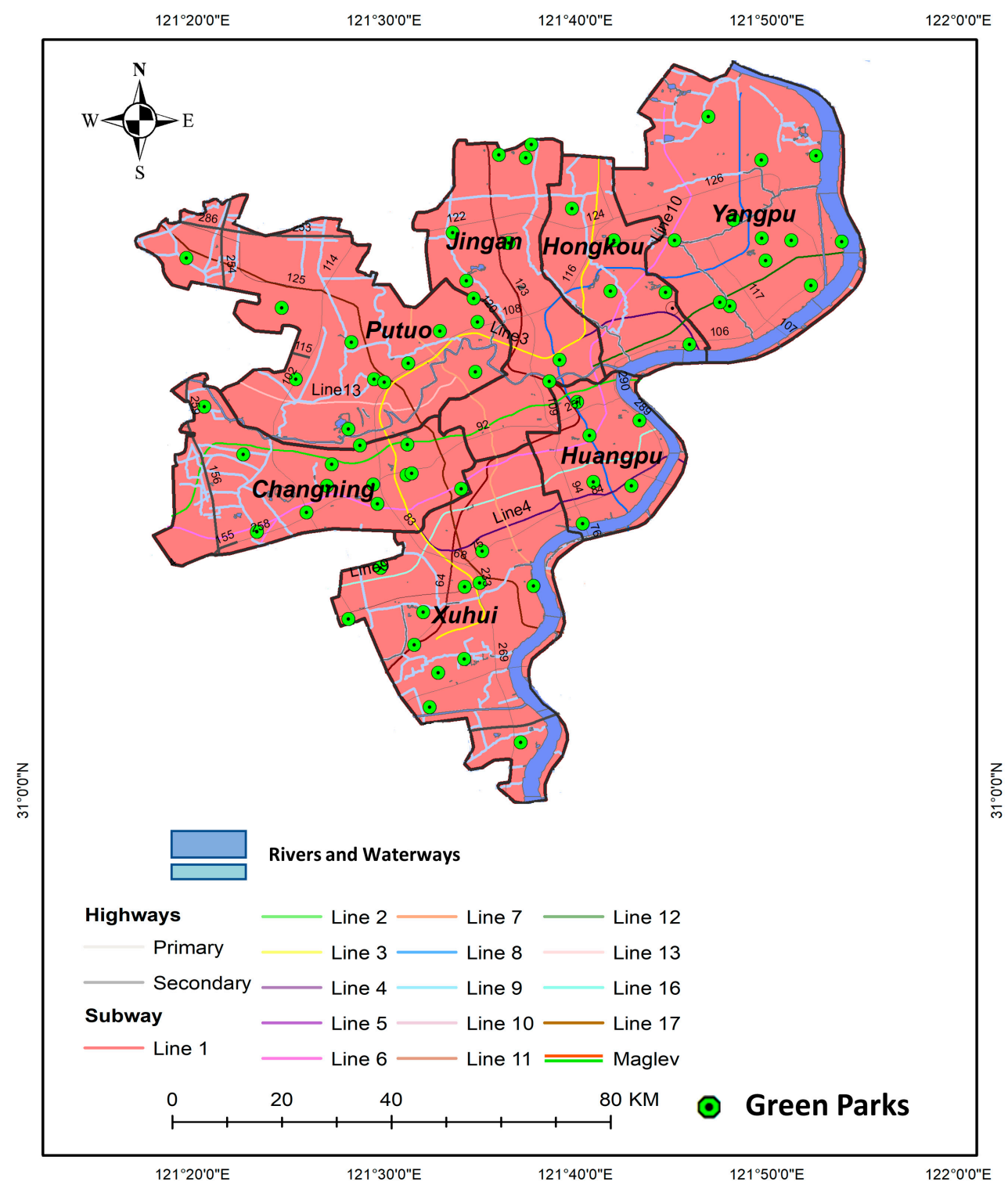

Figure 6. Green park locations after filtration.

We utilized KDE to examine the spatial distribution of check-in data and ArcGIS for visualization to investigate the Weibo geolocation check-in data. Figure 7 indicates the overall check-in density between July 2014 and June 2017. The red spots show higher human density, higher levels of activity, and a higher percentage of social media usage. It is unsurprising that the green parks in Putuo District have large clusters of activities. 


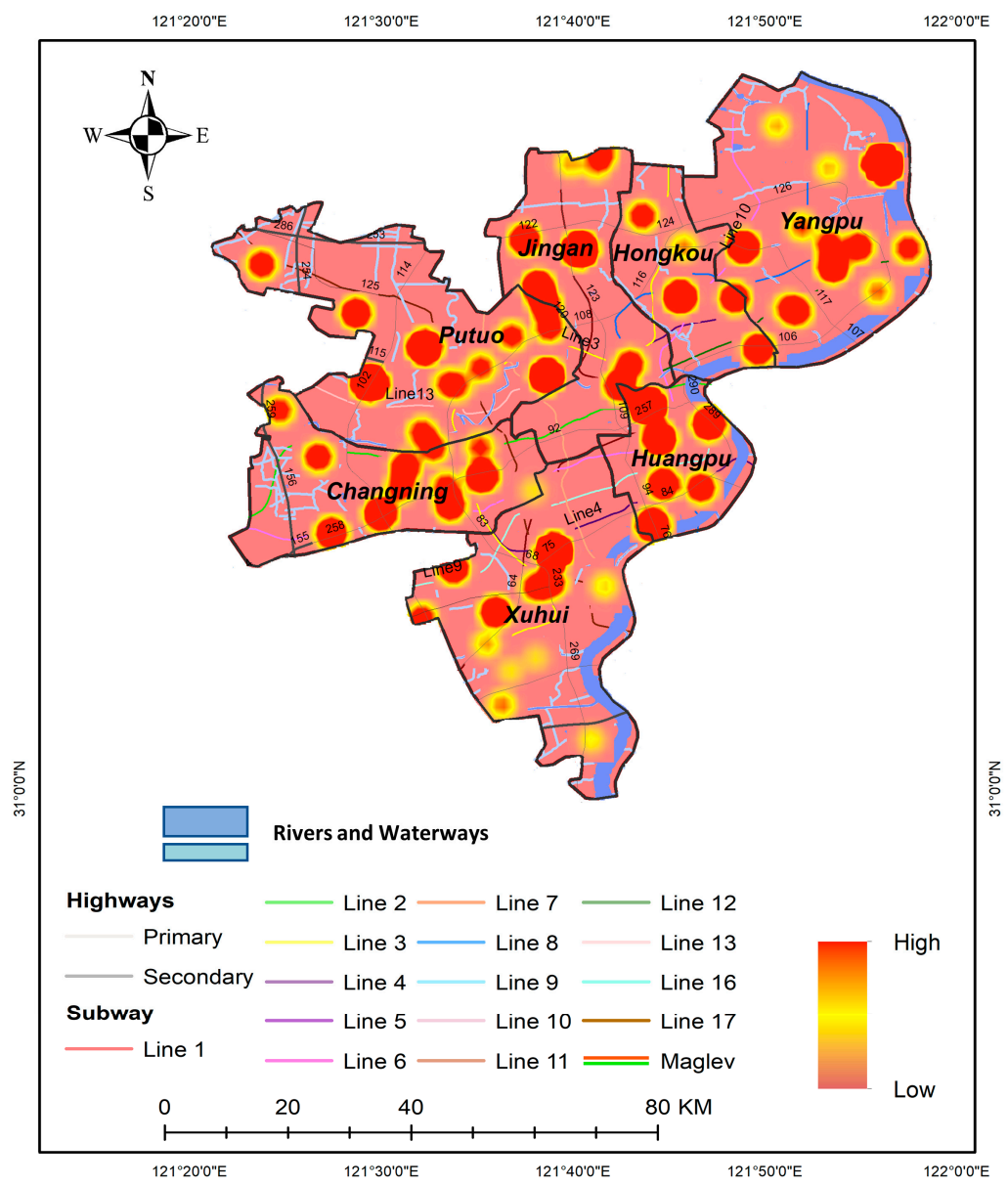

Figure 7. Check-in density.

Figure 8 presents the overall check-in density in all the districts, which has been divided into seven. Our results show that the most check-ins were found in Putuo, Huangpu, and Yangpu Districts.
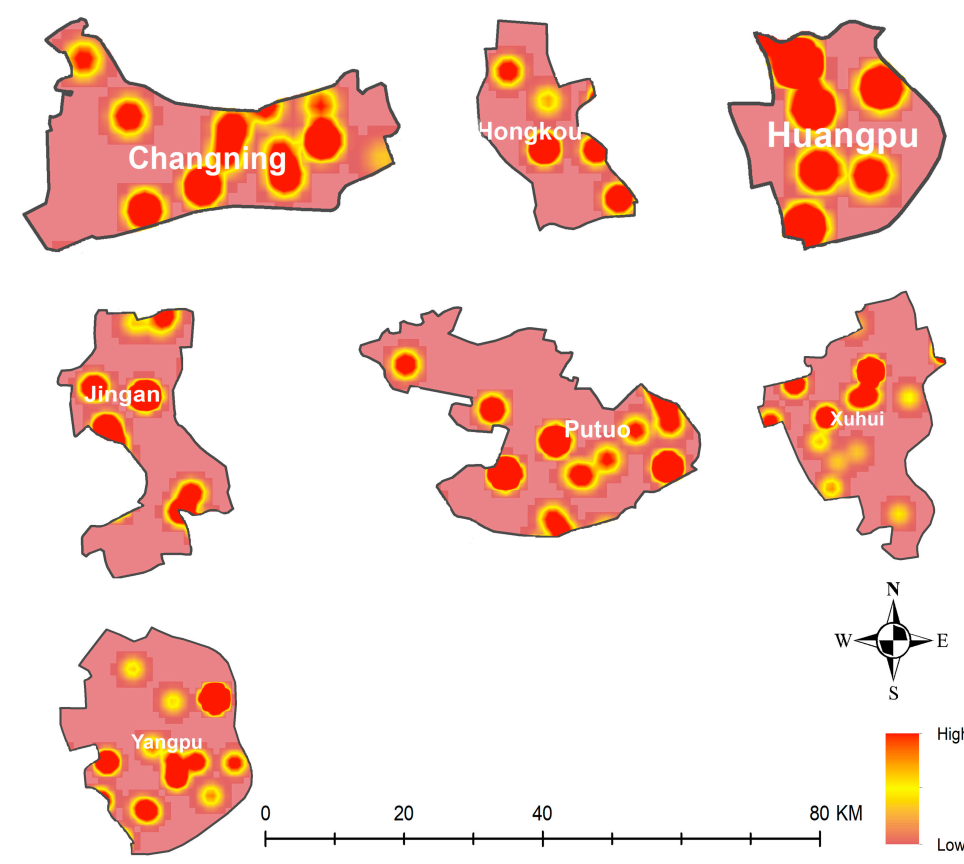

$80 \mathrm{KM}$

Figure 8. Check-in density in the districts. 
Figure 9 shows the temporal differences in the number of visitors over 24 hours. Although visitors contributed in all periods of the day, the maximum number of check-ins were made between 2:00 p.m. and up to 6:00 p.m. in the parks considered in the research. The trend keeps increasing until between 10:00 p.m. and midnight.

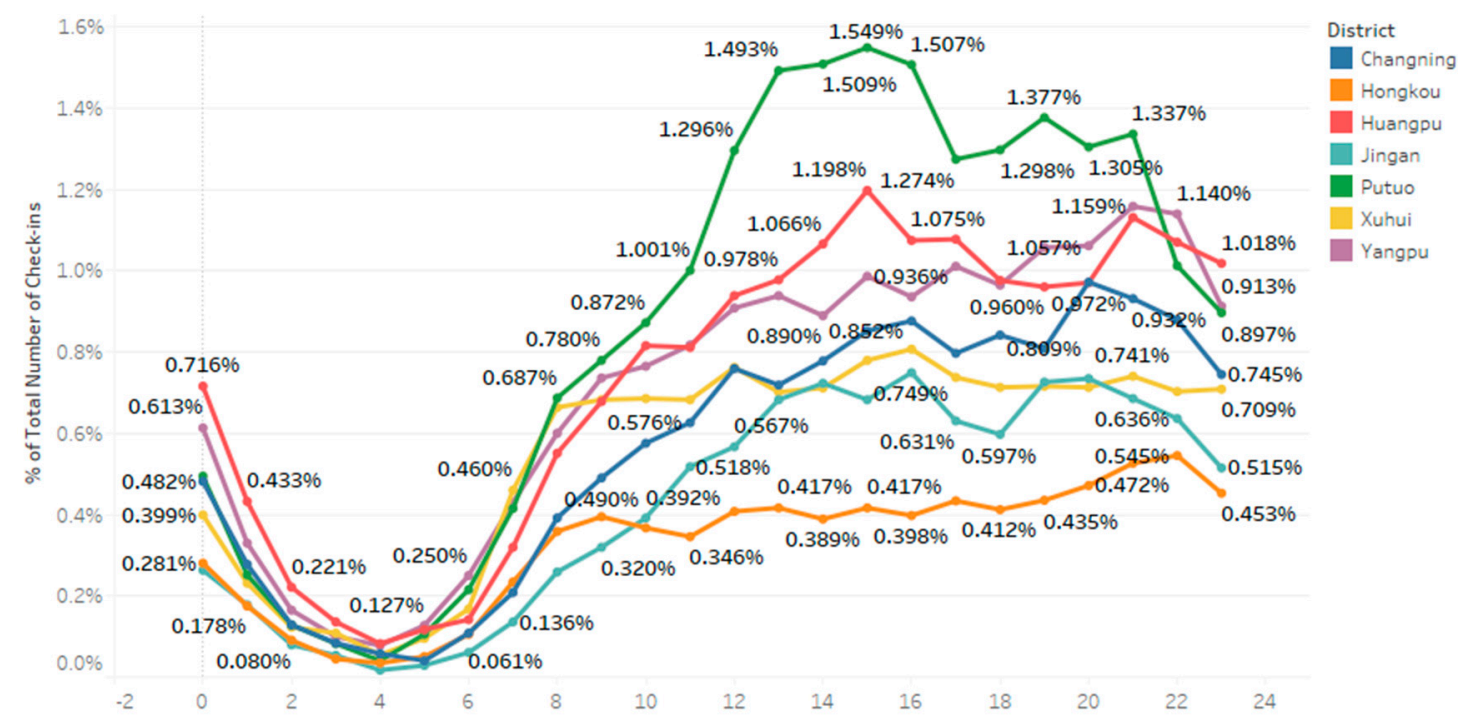

Figure 9. Absolute numbers per hour.

Figure 10 shows the district percentage for the three-year check-in dataset in the downtown area of Shanghai, revealing the differences in the check-in behavior of users in different districts. The number of check-ins in Putuo and Huangpu were really high compared to other districts, which makes Putuo District famous for visitors, which is why the density was high in this district compared to others. The reason for this is that Putuo District is larger in area, and population is also higher than other districts, which is why Putuo District is denser than others.

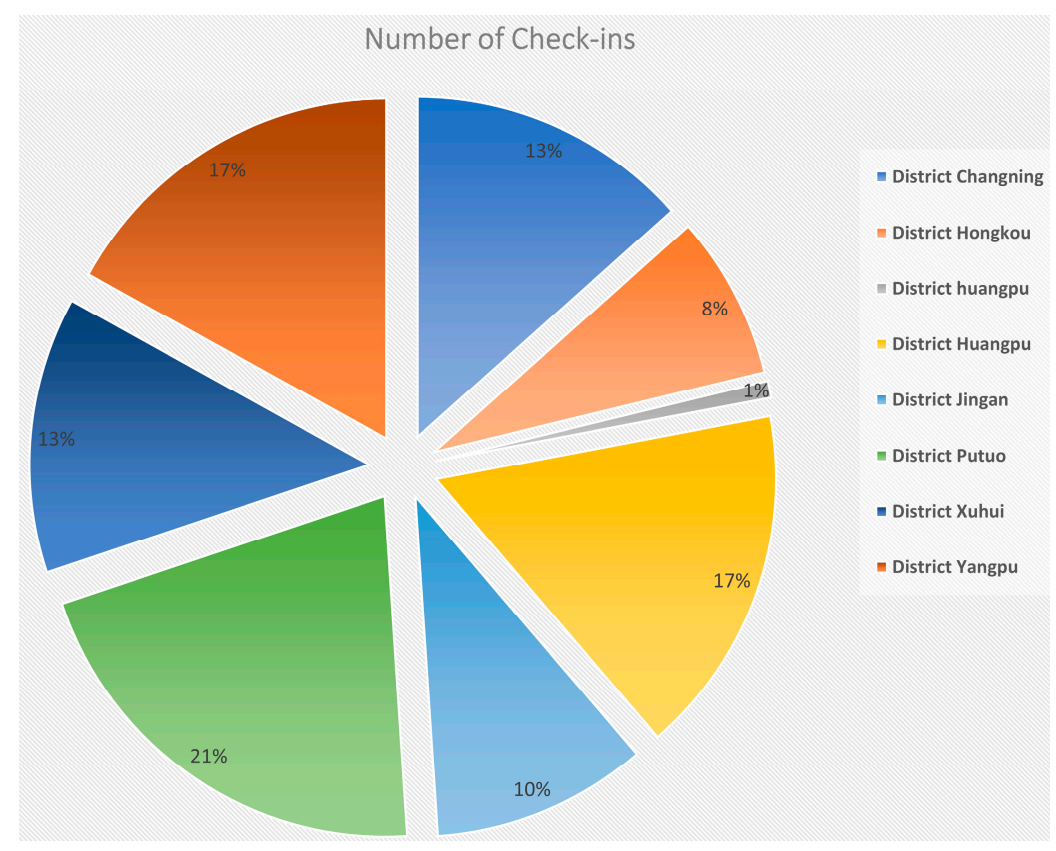

Figure 10. Percentage of check-ins in the districts. 
With nearly an equal number of check-ins, every weekday has fewer check-ins than Saturday and Sunday, and the weekly patterns are quite normal. Figure 11 describes the general pattern of weekly check-ins. On weekends, the number of check-ins is high in Yangpu District compared to the others. It reveals that mostly of the check-ins found on weekends (Saturday and Sunday) in every district. The interesting thing to note here is that Yangpu and Putuo Districts have higher numbers of check-ins on weekends but lesser visitation rates on weekdays.

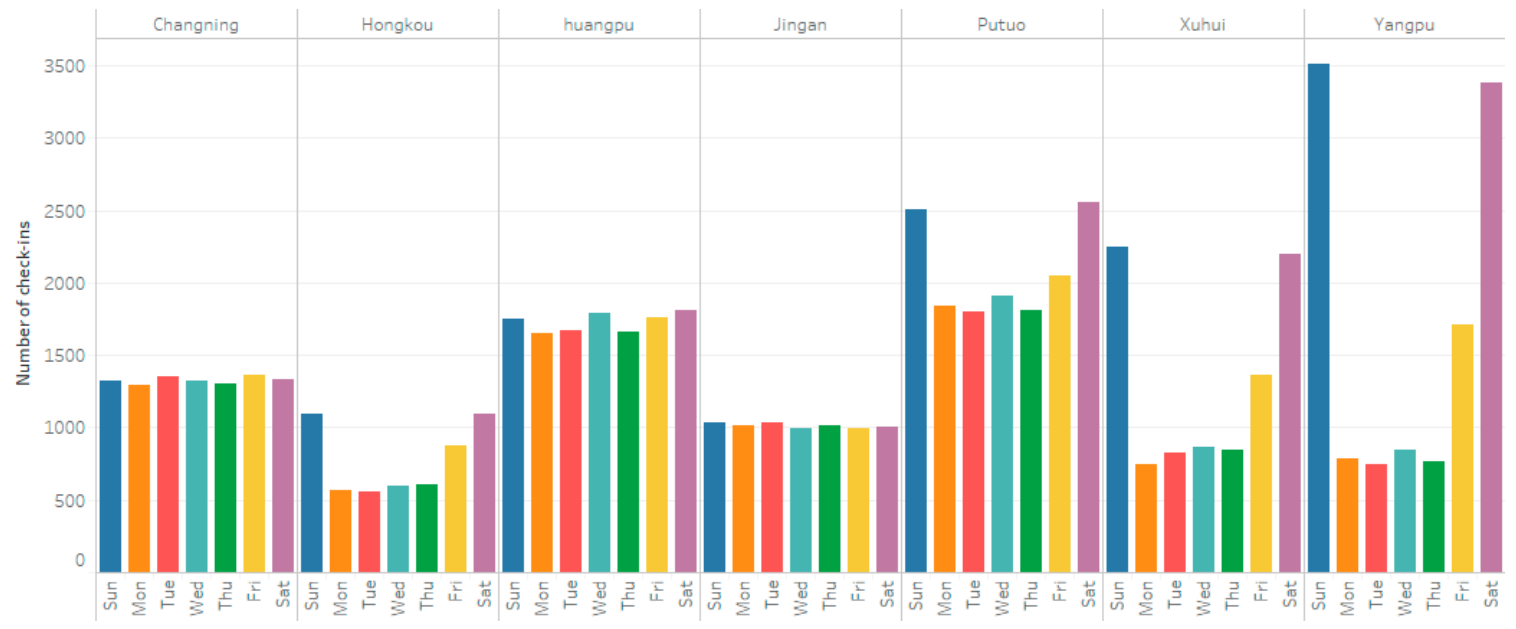

Figure 11. Weekly trends in green parks.

This result indicates that Shanghai's green parks are fast becoming popular recreational destinations for the people of Shanghai. Figure 12 shows the most popular parks in our study area based on the number of check-ins. Mostly people visit these parks in the city center and share their experience by posting on Weibo. Table 4 also represents the number of check-ins in famous parks.

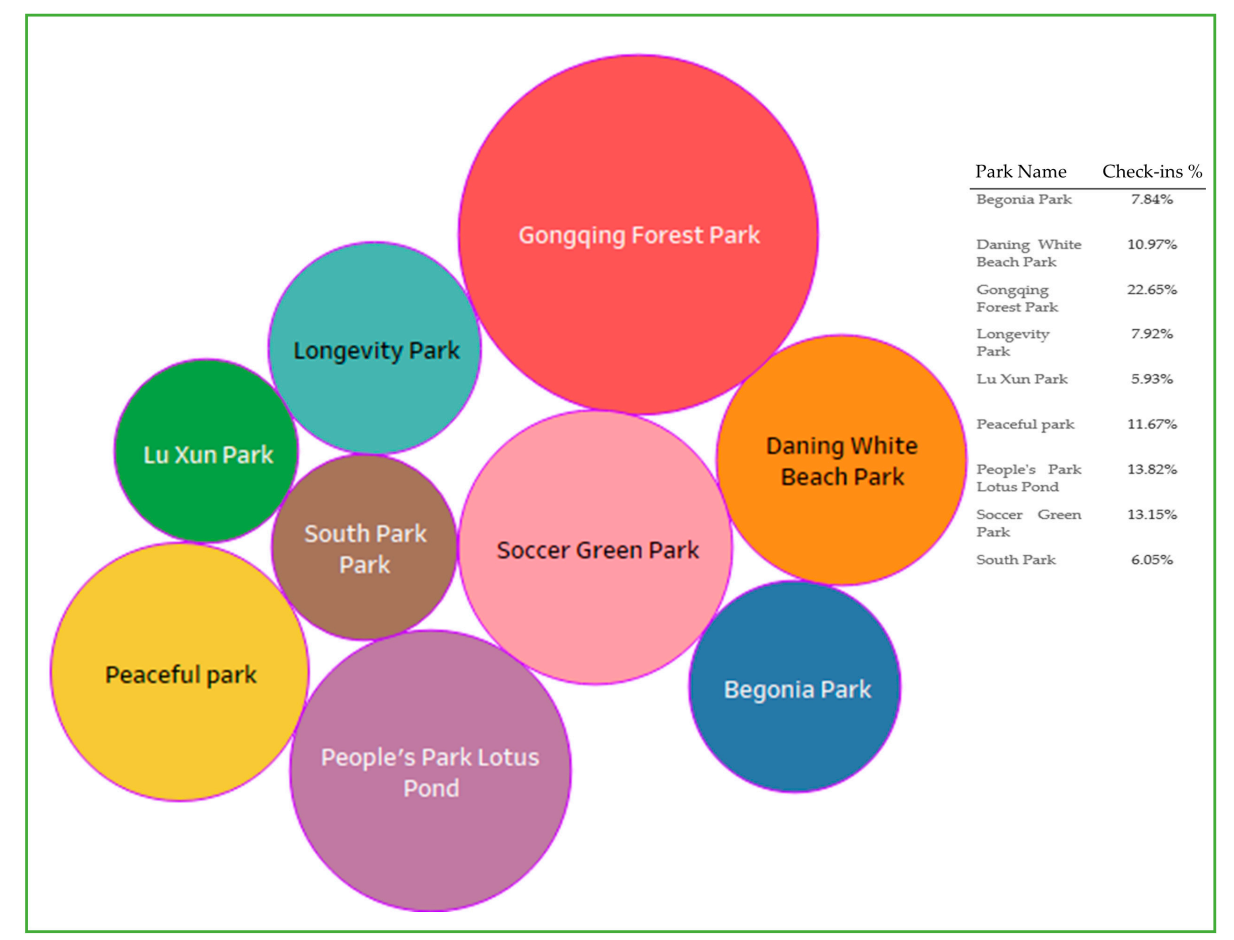

Figure 12. The most popular parks according to number of check-ins. 
Table 4. Number of check-ins in the famous parks.

\begin{tabular}{ccc}
\hline Name of Park & Number of Check-Ins & Check-Ins \% \\
\hline Gongqing Forest Park & 6144 & $22.65 \%$ \\
People's Park Lotus Pond & 3749 & $13.82 \%$ \\
Soccer Green Park & 3567 & $13.15 \%$ \\
Peaceful park & 3164 & $11.67 \%$ \\
Daning White Beach Park & 2975 & $10.97 \%$ \\
Longevity Park & 2147 & $7.92 \%$ \\
Begonia Park & 2126 & $7.84 \%$ \\
South Park & 1642 & $6.05 \%$ \\
Luxun Park & 6144 & $5.93 \%$ \\
\hline
\end{tabular}

Table 5 shows the number of check-ins for the districts, days, and gender.

Table 5. Overall statistics.

\begin{tabular}{ccccccccc}
\hline District & Gender & Sun & Mon & Tue & Wed & Thu & Fri & Sat \\
\hline \multirow{2}{*}{ Changning } & F & $1.20 \%$ & $1.14 \%$ & $1.21 \%$ & $1.16 \%$ & $1.15 \%$ & $1.22 \%$ & $1.13 \%$ \\
& M & $0.71 \%$ & $0.73 \%$ & $0.75 \%$ & $0.76 \%$ & $0.73 \%$ & $0.75 \%$ & $0.80 \%$ \\
Hongkou & F & $0.85 \%$ & $0.47 \%$ & $0.49 \%$ & $0.54 \%$ & $0.55 \%$ & $0.72 \%$ & $0.87 \%$ \\
& M & $0.73 \%$ & $0.35 \%$ & $0.32 \%$ & $0.32 \%$ & $0.33 \%$ & $0.55 \%$ & $0.70 \%$ \\
Huangpu & F & $1.54 \%$ & $1.42 \%$ & $1.49 \%$ & $1.57 \%$ & $1.49 \%$ & $1.58 \%$ & $1.56 \%$ \\
& M & $0.99 \%$ & $0.97 \%$ & $0.93 \%$ & $1.02 \%$ & $0.91 \%$ & $0.96 \%$ & $1.05 \%$ \\
Jingan & F & $0.94 \%$ & $0.93 \%$ & $0.89 \%$ & $0.91 \%$ & $0.88 \%$ & $0.87 \%$ & $0.90 \%$ \\
& M & $0.56 \%$ & $0.53 \%$ & $0.60 \%$ & $0.54 \%$ & $0.58 \%$ & $0.57 \%$ & $0.55 \%$ \\
Putuo & F & $2.19 \%$ & $1.68 \%$ & $1.68 \%$ & $1.74 \%$ & $1.70 \%$ & $1.84 \%$ & $2.32 \%$ \\
& M & $1.44 \%$ & $0.98 \%$ & $0.93 \%$ & $1.02 \%$ & $0.93 \%$ & $1.13 \%$ & $1.38 \%$ \\
Xuhui & $\mathrm{F}$ & $1.72 \%$ & $0.62 \%$ & $0.68 \%$ & $0.73 \%$ & $0.74 \%$ & $1.13 \%$ & $1.74 \%$ \\
& $\mathrm{M}$ & $1.53 \%$ & $0.46 \%$ & $0.52 \%$ & $0.52 \%$ & $0.49 \%$ & $0.83 \%$ & $1.45 \%$ \\
Yangpu & $\mathrm{F}$ & $2.78 \%$ & $0.67 \%$ & $0.63 \%$ & $0.75 \%$ & $0.65 \%$ & $1.36 \%$ & $2.71 \%$ \\
& $\mathrm{M}$ & $2.30 \%$ & $0.47 \%$ & $0.45 \%$ & $0.47 \%$ & $0.46 \%$ & $1.12 \%$ & $2.18 \%$ \\
\hline
\end{tabular}

We investigated gender (male and female) data in Shanghai to explore the check-in numbers and behavior. A comparison of male and female user check-ins in days of the week, as well as in districts, examines the difference between male and female visitors in Shanghai. We used the relative difference $\left(d_{r}\right)[48,49]$ to estimate the gender differences in Shanghai districts and also for days of the week. It is frequently used as a quantitative indicator of superiority control and quality guarantee and is stated as follows:

$$
d_{r}=\frac{\left|P_{m}-P_{f}\right|}{\left(\frac{\left|P_{m}\right|+\left|P_{f}\right|}{2}\right)}
$$

Tables 6 and 7 show the results of the relative difference calculated by using differences between male and female users in a week, and districts are pragmatically shown at the cumulative level. We calculated the gender differences of check-ins by the week and district as a percentile of total accumulated check-ins generated during the course of the study. Table 6 shows the outcomes of the relative difference computed in a week using Equation (3). For Friday and Saturday, the comparative difference values were substantially higher than other days. Table 6 reveals that gender differences of Friday, Saturday, and Sunday are higher than the other days, and likewise, Table 7 shows the outcomes of the relative difference computed in districts, and it reveals that gender differences in Putuo, Xuhui, and Yangpu Districts are higher. 
Table 6. Gender difference during the week. dr: relative difference.

\begin{tabular}{ccccc}
\hline Days & Check-Ins & Female & Male & dr \\
\hline Mon & $11.40 \%$ & $6.92 \%$ & $4.48 \%$ & 0.518 \\
Tue & $11.56 \%$ & $7.06 \%$ & $4.49 \%$ & 0.511 \\
Wed & $12.04 \%$ & $7.39 \%$ & $4.65 \%$ & 0.518 \\
Thu & $11.58 \%$ & $7.17 \%$ & $4.42 \%$ & 0.512 \\
Fri & $14.62 \%$ & $8.71 \%$ & $5.91 \%$ & 0.519 \\
Sat & $19.32 \%$ & $11.22 \%$ & $8.10 \%$ & 0.518 \\
Sun & $19.49 \%$ & $11.22 \%$ & $8.27 \%$ & 0.528 \\
\hline
\end{tabular}

Table 7. Gender difference between the districts.

\begin{tabular}{ccccc}
\hline District & Check-Ins & Female & Male & dr \\
\hline Changning & $13.43 \%$ & $8.21 \%$ & $5.22 \%$ & 0.516 \\
Hongkou & $7.79 \%$ & $4.49 \%$ & $3.30 \%$ & 0.517 \\
Huangpu & $17.48 \%$ & $10.66 \%$ & $6.83 \%$ & 0.508 \\
Jingan & $10.24 \%$ & $6.31 \%$ & $3.93 \%$ & 0.514 \\
Putuo & $20.93 \%$ & $13.13 \%$ & $7.80 \%$ & 0.478 \\
Xuhui & $13.15 \%$ & $7.35 \%$ & $5.80 \%$ & 0.563 \\
Yangpu & $16.98 \%$ & $9.54 \%$ & $7.44 \%$ & 0.549 \\
\hline
\end{tabular}

The gender differences in the districts and days is also represented in Figure 13.

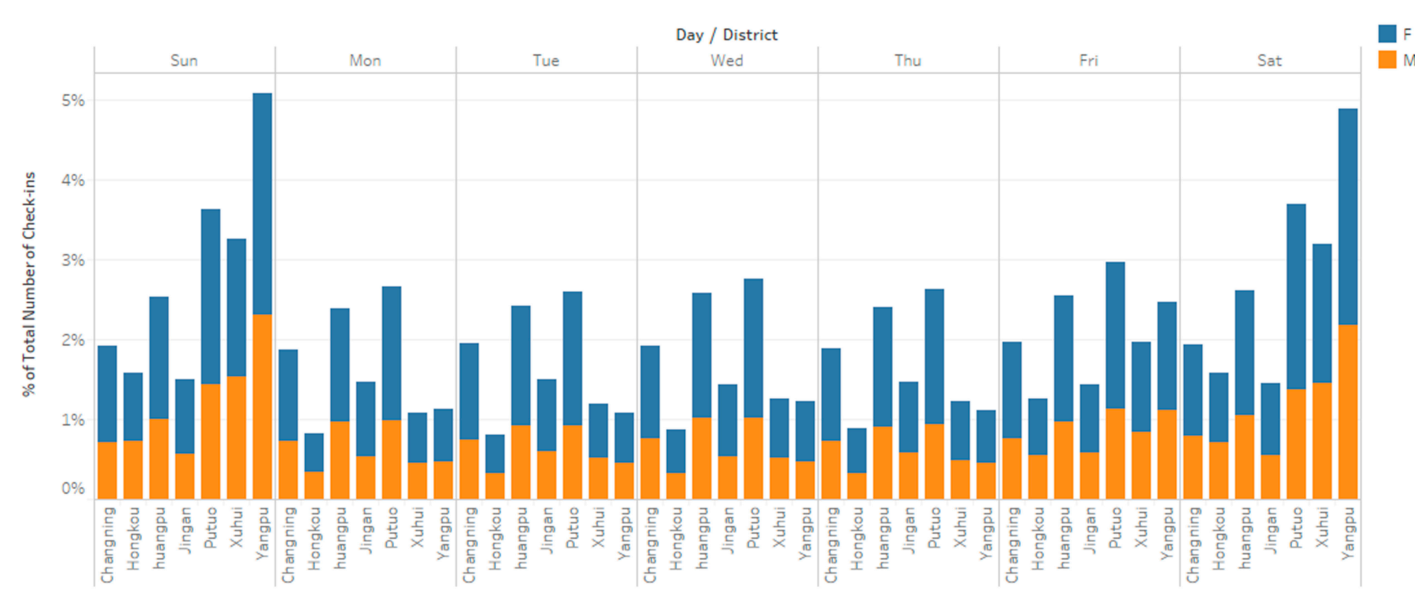

(a)

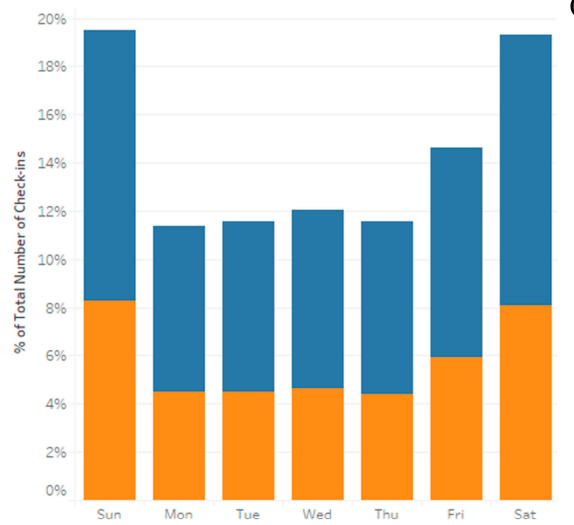

(b)

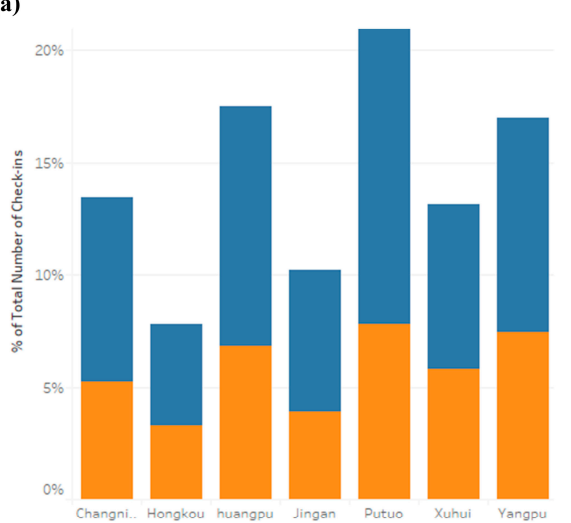

(c)

Figure 13. (a) Gender differences in the districts/days, (b) gender difference weekly, and (c) gender differences in the districts. 


\section{Discussion}

This study used geolocated social network check-in data as a proxy for estimating the number of visits to urban parks. This approach is time-efficient and labor-intensive and provides outstanding spatial coverage. In this research, we performed a temporal analysis of sex-based variations in human behavioral patterns to investigate trends of hourly and daily check-ins, along with weekdays and weekends. The findings revealed that women are much more likely to use social media throughout the weekdays compared to men in almost all districts. In the city center, Putuo District was found to have a high density of check-ins. As the research shows, Weibo data constitute a valuable tool for the evaluation of urban green park functionality and the study of spatiotemporal factors. The advantage of using social media data to evaluate urban green spaces is that we can collect contextual and large-scale knowledge about an entire city in more detail. For this reason, Weibo data are the best source for geospatial data analysis.

The kernel density estimation is a tool for determining the probability density function and is a must-have that allows the user to examine the distribution of probability studied better than when using a traditional histogram. The kernel technique, unlike the histogram, provides smooth estimation, uses the locations of all sample points, and, more convincingly, implies multimodality. KDE is a function in which events are balanced according to their distances and necessary two parameters. The first of these is the bandwidth, the distance of control. Bandwidth selection has a big effect on performance. The second parameter is the weighting function $\mathrm{K}$, most often a normal function. The bandwidth of the kernel is a free parameter that displays a strong impact on the resulting estimate. Compared to the commonly used histogram, the estimator of kernel density offers many advantages. It is a smooth curve and, therefore, better displays the details and uses the locations of all sample points, so the information included in the sample should be better revealed. KDE calculates smooth distributions by excluding the local noise to a particular degree, which minimizes the error by providing a nonparametric probability distribution with an optimum bandwidth. We applied the kernel density estimation in green parks, and according to our Weibo data, the number of check-ins in Putuo and Huangpu Districts are higher than the other districts, and it can been seen that, after applying the KDE, we have same results that makes Putuo and Huangpu denser than others due to large clusters of density. For example, we can also get the better results by applying the KDE if we take a mean number of people in two or more than two parks. The role of the DKE in green spaces and the environment are really important and have been used by many researchers in the research of green parks $[31,50,51]$.

Availability of the data is the main barrier in LBSN studies, mostly due to security and personal privacy. Sharing the present geolocation of visitors and their social circle using LBSNs creates serious issues over individual confidentiality. Personal information is an issue not only for individuals but, also, for institutional or organizational employers who share their information on LBSNs. Quite often, users share their personal data on a voluntary basis, whereas, at other times, data could be collected extrinsically by giving users various incentives and benefits for their details. User locations could be recognized by LBSN services like Google Latitude, Fire Eagle, and WeChat Nearby. Several LBSN services offer additional features that recognize the location of your friend as well [25]. In summary, as the check-in data is too raw and imprecise for assessing the transfer of activities from one location to another, the data cannot reliably reflect the precise nature of district user progression.

This methodology has its own limitations, but, because we cannot access measured visitor rates, we have been unable to determine if there was a healthy association between the check-in and visitation data observed in the urban-area planning and evaluation. Unlike conventional census data, it is of major consideration that social media data usually do not include clear information such as ethnicity and family status. There are, however, ways to obtain these indirectly [34]. The relationship between Weibo's check-in frequency and actual visitation can vary throughout green parks. The factors affecting the changing conduct of urban behavior in space and time should be investigated. This study's extensive spatial scope offers valuable knowledge that could boost urban green space planning and growth in other major cities. With the effective use of urban green areas, there is considerable potential 
to promote moderate-to-strong physical activity among urban residents. These findings highlight the importance of using urban green parks to boost the health of people living in cities all over the world.

\section{Conclusions and Future Work}

In this study, we applied a big data methodology to overcome the issue of environmental justice linked to the spatial provision of urban green parks in Shanghai. We utilized geotagged Weibo check-in data as park visit indicators in seven districts of Shanghai, which are called the city center or downtown area, and investigated the number of check-in visits. We achieved an in-depth experimental analysis of check-in behavior that used intensity maps and patterns from LBSN data. The findings reveal the distribution of users in parks by check-in data and show that Weibo data is feasible for this study, because it has a lot of potential compared to traditional data. The outcomes show that Putuo District is the center of activities according to the number of check-ins. The total number of Weibo users, depending on the hour of the day, shows that the peak time of visits to green parks is from noon to midnight. We also explored the famous parks in our study area, which are mostly situated in Putuo and Xuhui Districts. Lastly, gender-based variations were measured in green park visitors, and findings reveal that female visitors or users are more involved in their use of social media services when visiting green parks. Our results also show that visitors visit the green parks until midnight, so planners should pay more attention to the facilities and also boost up the surveillance system, because there are some park-like forests where there could be some security concerns. Using medical data with this type of data has great significance, because green parks provide a healthy environment and a place where visitors can engage in different types of activity.

Author Contributions: Qi Liu, Hidayat Ullah, and Wanggen Wan conceived the research; Hidayat Ullah and Saqib Ali Haidery designed the research; Hidayat Ullah, Saqib Ali Haidery, Qi Liu, Tong Qu, and Li Hou performed the simulations; Hidayat Ullah, Saqib Ali Haidery, and Qi Liu wrote the article; and Wanggen Wan and Zhangyou Peng proofread the article for language editing. All authors have read and agreed to the published version of the manuscript.

Funding: This work was supported by the project of Shanghai Science and Technology Commission (No: 18510760300), Anhui Natural Science Foundation (No: 1908085MF178), and Anhui Excellent Young Talents Support Program Project (No: gxyqZD2019069).

Conflicts of Interest: The authors declare no conflict of interest.

\section{References}

1. Cetin, M. Determining the bioclimatic comfort in Kastamonu City. Environ. Monit. Assess. 2015, 187, 640. [CrossRef] [PubMed]

2. Lee, A.; Maheswaran, R. The health benefits of urban green spaces: A review of the evidence. J. Public Heal. 2010, 33, 212-222. [CrossRef] [PubMed]

3. Haq, S.M.A. Urban Green Spaces and an Integrative Approach to Sustainable Environment. J. Environ. Prot. 2011, 2, 601-608. [CrossRef]

4. Amoly, E.; Dadvand, P.; Forns, J.; López-Vicente, M.; Basagaña, X.; Julvez, J.; Alvarez-Pedrerol, M.; Nieuwenhuijsen, M.J.; Sunyer, J. Green and Blue Spaces and Behavioral Development in Barcelona Schoolchildren: The BREATHE Project. Environ. Health Perspect. 2014, 122, 1351-1358. [CrossRef] [PubMed]

5. Hand, K.L.; Freeman, C.; Seddon, P.J.; Recio, M.R.; Stein, A.; Van Heezik, Y. The importance of urban gardens in supporting children's biophilia. Proc. Natl. Acad. Sci. USA 2017, 114, 274-279. [CrossRef] [PubMed]

6. Richardson, E.A.; Pearce, J.; Mitchell, R.; Kingham, S. Role of physical activity in the relationship between urban green space and health. Public Health 2013, 127, 318-324. [CrossRef] [PubMed]

7. Zhou, W.; Wang, J.; Cadenasso, M. Effects of the spatial configuration of trees on urban heat mitigation: A comparative study. Remote Sens. Environ. 2017, 195, 1-12. [CrossRef]

8. Cohen, D.A.; Marsh, T.; Williamson, S.; Derose, K.P.; Martinez, H.; Setodji, C.; McKenzie, T.L. Parks and physical activity: Why are some parks used more than others? Prev. Med. 2009, 50, S9-S12. [CrossRef] 
9. Wendel, H.E.W.; Zarger, R.; Mihelcic, J.R. Accessibility and usability: Green space preferences, perceptions, and barriers in a rapidly urbanizing city in Latin America. Landsc. Urban Plan. 2012, 107, 272-282. [CrossRef]

10. Tenkanen, H.; Di Minin, E.; Heikinheimo, V.; Hausmann, A.; Herbst, M.; Kajala, L.; Toivonen, T. Instagram, Flickr, or Twitter: Assessing the usability of social media data for visitor monitoring in protected areas. Sci. Rep. 2017, 7, 17615. [CrossRef]

11. Wood, S.A.; Guerry, A.D.; Silver, J.M.; Lacayo-Emery, M. Using social media to quantify nature-based tourism and recreation. Sci. Rep. 2013, 3, 2976. [CrossRef] [PubMed]

12. WHO Regional Office for Europe. Urban Green Spaces and Health; WHO Regional Office for Europe: Copenhagen, Denmark, 2016.

13. Nawrocka, A.; Mynarski, W. Objective Assessment of Adherence to Global Recommendations on Physical Activity for Health in Relation to Spirometric Values in Nonsmoker Women Aged 60-75 Years. J. Aging Phys. Act. 2017, 25, 123-127. [CrossRef] [PubMed]

14. Roberts, H.V. Using Twitter data in urban green space research: A case study and critical evaluation. Appl. Geogr. 2017, 81, 13-20. [CrossRef]

15. Martí, P.; Serrano-Estrada, L.; Nolasco-Cirugeda, A. Using locative social media and urban cartographies to identify and locate successful urban plazas. Cities 2017, 64, 66-78. [CrossRef]

16. Smiley, M.J.; Roux, A.V.D.; Brines, S.J.; Brown, D.; Evenson, K.R.; Rodríguez, D.A. A spatial analysis of health-related resources in three diverse metropolitan areas. Health Place 2010, 16, 885-892. [CrossRef] [PubMed]

17. Thornton, L.; Pearce, J.; Macdonald, L.; Lamb, K.E.; Ellaway, A. Does the choice of neighbourhood supermarket access measure influence associations with individual-level fruit and vegetable consumption? A case study from Glasgow. Int. J. Heal. Geogr. 2012, 11, 29. [CrossRef]

18. Thornton, L.; Pearce, J.; Kavanagh, A. Using Geographic Information Systems (GIS) to assess the role of the built environment in influencing obesity: A glossary. Int. J. Behav. Nutr. Phys. Act. 2011, 8, 71. [CrossRef]

19. Demographia World Urban Areas, 8th ed.; Available online: http://www.demographia.com/db-worldua.pdf (accessed on 28 December 2012).

20. Xiao, Y.; Wang, Z.; Li, Z.; Tang, Z. An assessment of urban park access in Shanghai-Implications for the social equity in urban China. Landsc. Urban Plan. 2017, 157, 383-393. [CrossRef]

21. Department of Economic and Social Affairs. World Urbanization Prospects the 2014 Revision; United Nations: New York, NY, USA, 2014.

22. Xiong, X.; Jin, C.; Chen, H.; Luo, L. Using the Fusion Proximal Area Method and Gravity Method to Identify Areas with Physician Shortages. PLoS ONE 2016, 11, e0163504. [CrossRef]

23. Shen, J.; Kee, G. Development and Planning in Seven Major Coastal Cities in Southern and Eastern China; Springer Science and Business Media LLC: Berlin/Heidelberg, Germany, 2017; Volume 120.

24. Ebrahimpour, Z.; Wan, W.; García, J.L.V.; Cervantes, O.; Hou, L. Analyzing Social-Geographic Human Mobility Patterns Using Large-Scale Social Media Data. ISPRS Int. J. Geo-Inf. 2020, 9, 125. [CrossRef]

25. Weibo Statistics. Available online: http://ir.weibo.com/news-releases/news-release-details/weibocorporation-report-fourth-quarter-and-fiscal-year-2018 (accessed on 10 June 2019).

26. Shen, Y.; Sun, F.; Che, Y. Public green spaces and human wellbeing: Mapping the spatial inequity and mismatching status of public green space in the Central City of Shanghai. Urban For. Urban Green. 2017, 27, 59-68. [CrossRef]

27. Zhen, F.; Cao, Y.; Qin, X.; Wang, B. Delineation of an urban agglomeration boundary based on Sina Weibo microblog 'check-in' data: A case study of the Yangtze River Delta. Cities 2017, 60, 180-191. [CrossRef]

28. Shen, Y.; Karimi, K. Urban function connectivity: Characterisation of functional urban streets with social media check-in data. Cities 2016, 55, 9-21. [CrossRef]

29. Keeler, B.L.; Wood, S.A.; Polasky, S.; Kling, C.L.; Filstrup, C.T.; Downing, J.A. Recreational demand for clean water: Evidence from geotagged photographs by visitors to lakes. Front. Ecol. Environ. 2015, 13, 76-81. [CrossRef]

30. Consensus Data. Available online: http://tj.sh.gov.cn/html/sjfb/201901/1003014.html (accessed on 20 January 2020).

31. Ullah, H.; Wan, W.; Haidery, S.A.; Khan, N.U.; Ebrahimpour, Z.; Muzahid, A.A.M. Spatiotemporal Patterns of Visitors in Urban Green Parks by Mining Social Media Big Data Based Upon WHO Reports. IEEE Access 2020, 8, 39197-39211. [CrossRef] 
32. Ye, X.; Wang, T.; Ye, X.; Zhu, J.; Lee, J. Using Social Media for Emergency Response and Urban Sustainability: A Case Study of the 2012 Beijing Rainstorm. Sustainability 2015, 8, 25. [CrossRef]

33. Xie, Z.; Yan, J. Kernel Density Estimation of traffic accidents in a network space. Comput. Environ. Urban Syst. 2008, 32, 396-406. [CrossRef]

34. Khan, N.U.; Wan, W.; Yu, S. Spatiotemporal Analysis of Tourists and Residents in Shanghai Based on Location-Based Social Network's Data from Weibo. ISPRS Int. J. Geo-Inf. 2020, 9, 70. [CrossRef]

35. Silverman, B.W. Density Estimation for Statistics and Data Analysis; Informa UK Limited: London, UK, 2018.

36. Maroko, A.R.; Maantay, J.; Sohler, N.L.; Grady, K.L.; Arno, P.S. The complexities of measuring access to parks and physical activity sites in New York City: A quantitative and qualitative approach. Int. J. Heal. Geogr. 2009, 8, 34. [CrossRef]

37. Yu, W.; Ai, T.; Shao, S. The analysis and delimitation of Central Business District using network kernel density estimation. J. Transp. Geogr. 2015, 45, 32-47. [CrossRef]

38. Yu, W.; Ai, T.; He, Y.; Shao, S. Spatial co-location pattern mining of facility points-of-interest improved by network neighborhood and distance decay effects. Int. J. Geogr. Inf. Sci. 2016, 31, 280-296. [CrossRef]

39. Ying, L.; Shen, Z.; Chen, J.; Fang, R.; Chen, X.; Jiang, R. Spatiotemporal patterns of road network and road development priority in three parallel rivers region in Yunnan, China: An evaluation based on modified kernel distance estimate. Chin. Geogr. Sci. 2014, 24, 39-49. [CrossRef]

40. Wu, C.; Ye, X.; Ren, F.; Wan, Y.; Ning, P.; Du, Q. Spatial and Social Media Data Analytics of Housing Prices in Shenzhen, China. PLoS ONE 2016, 11, e0164553. [CrossRef] [PubMed]

41. King, T.L.; Bentley, R.; Thornton, L.; Kavanagh, A.M. Using kernel density estimation to understand the influence of neighbourhood destinations on BMI. BMJ Open 2016, 6, e008878. [CrossRef]

42. Khan, N.U.; Wan, W.; Yu, S. Location-Based Social Network's Data Analysis and Spatio-Temporal Modeling for the Mega City of Shanghai, China. ISPRS Int. J. Geo-Inf. 2020, 9, 76. [CrossRef]

43. Hasan, S.; Zhan, X.; Ukkusuri, S. Understanding urban human activity and mobility patterns using large-scale location-based data from online social media. In Proceedings of the 2nd ACM SIGKDD International Workshop, Chicago, IL, USA, 14 August 2013; Volume 1. [CrossRef]

44. Li, L.; Goodchild, M.F.; Xu, B. Spatial, temporal, and socioeconomic patterns in the use of Twitter and Flickr. Cartogr. Geogr. Inf. Sci. 2013, 40, 61-77. [CrossRef]

45. Sun, Y.; Fan, H.; Li, M.; Zipf, A. Identifying the city center using human travel flows generated from location-based social networking data. Environ. Plan. B Plan. Des. 2015, 43, 480-498. [CrossRef]

46. Yuan, N.J.; Zheng, Y.; Xie, X.; Wang, Y.; Zheng, K.; Xiong, H. Discovering Urban Functional Zones Using Latent Activity Trajectories. IEEE Trans. Knowl. Data Eng. 2014, 27, 712-725. [CrossRef]

47. Li, H.; Ge, Y.; Hong, R.; Zhu, H. Point-of-interest recommendations: Learning potential check-ins from friends. In Proceedings of the 22nd ACM SIGKDD International Conference on Knowledge Discovery and Data Mining, San Francisco, CA, USA, 13-17 August 2016; pp. 975-984.

48. Ullah, H.; Wan, W.; Haidery, S.A.; Khan, N.U.; Ebrahimpour, Z.; Luo, T. Analyzing the Spatiotemporal Patterns in Green Spaces for Urban Studies Using Location-Based Social Media Data. ISPRS Int. J. Geo-Inf. 2019, 8, 506. [CrossRef]

49. Van Iddekinge, C.H.; Lanivich, S.E.; Roth, P.L.; Junco, E. Social Media for Selection? Validity and Adverse Impact Potential of a Facebook-Based Assessment. J. Manag. 2016, 42, 1811-1835. [CrossRef]

50. Li, F.; Zhang, F.; Li, X.; Wang, P.; Liang, J.; Mei, Y.; Cheng, W.; Qian, Y. Spatiotemporal Patterns of the Use of Urban Green Spaces and External Factors Contributing to Their Use in Central Beijing. Int. J. Environ. Res. Public Heal. 2017, 14, 237. [CrossRef] [PubMed]

51. Liu, W.; Chen, W.; Dong, C. Spatial decay of recreational services of urban parks: Characteristics and influencing factors. Urban For. Urban Green. 2017, 25, 130-138. [CrossRef]

(C) 2020 by the authors. Licensee MDPI, Basel, Switzerland. This article is an open access article distributed under the terms and conditions of the Creative Commons Attribution (CC BY) license (http://creativecommons.org/licenses/by/4.0/). 